\title{
Software aus Deutschland ...
}

Globalisierung ist gerade in der IT viel mehr als ein modisches Buzzword. Da, um IT-Dienstleistungen zu erbringen, keine Güter transportiert werden müssen, eignen sich diese grundsätzlich besonders gut für die Verlagerung ins Ausland. Aber auch das Exportieren von Software ist ungleich einfacher als etwa der Verkauf von Autos in weit entfernte Weltgegenden. Dementsprechend hart ist der globale Wettbewerb. Wo es keine umfassenden Investitionen in industrielle Produktionsanlagen braucht, zählen vor allem die Menschen, ihre Ideen und Fähigkeiten - und, ob sie diese in ihren jeweiligen Ländern möglichst einfach und schnell in Geschäftsmodelle umsetzen

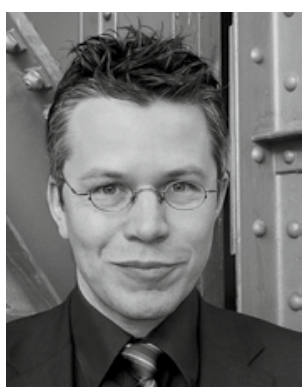

Peter Pagel

Chefredakteur

können, ohne dass ihnen der Staat Steine in den Weg legt. Ist Deutschland in dieser Hinsicht gut aufgestellt? Wo liegen hierzulande die Stärken, wo die Schwächen? Antworten auf diese Fragen geben die Autoren unseres Schwerpunktthemas. So viel vorab: Die Chancen, dass Deutschland auch in $\mathrm{Zu}-$ kunft ein bedeutender Standort für die Software-Industrie sein wird, stehen insgesamt betrachtet nicht schlecht.

Viele Grüße,

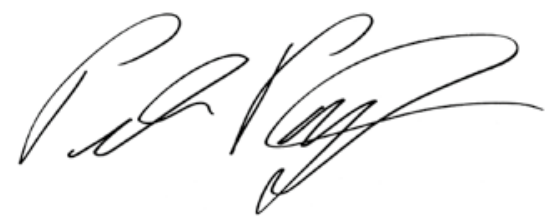

Peter Pagel, Chefredakteur 